\title{
CAPÍTULO 53: TREINAMENTO DE BOAS PRÁTICAS DE MANIPULAÇÃO DE ALIMENTOS PARA COMÉRCIO AMBULANTE DE GARANHUNS-PE
}

\section{CHAPTER 53: TRAINING GOOD PRACTICES IN FOOD HANDLING FOR AMBULANT TRADE IN GARANHUNS-PE}

\author{
Mirelly Costa da Silva ${ }^{1}$; Gerla Castello Branco Chinelate ${ }^{2}$
}

\begin{abstract}
Resumo
A aplicação de Boas Práticas de Manipulação e Procedimento Operacionais Padronizados em todos os serviços de alimentação, é de grande importância, tendo em vista que a falta de higiene e conscientização dos manipuladores de alimentos é uma das principais fontes de contaminação. O presente trabalho apresenta as atividades desenvolvidas em parceria com a Vigilância Sanitária Municipal do município de Garanhuns/PE. Desta forma o objetivo geral desse trabalho foi avaliar as condições higiênicas destes estabelecimentos, baseada em legislações sanitárias vigentes. Foram realizados o acompanhamento, orientações e treinamentos com os vendedores ambulantes e estabelecimentos durantes as festividades oficiais do calendário da cidade com o intuito de reduzir ao máximo os riscos contaminação, utilizando ferramentas de qualidade, para trabalhar a respeito da necessidade e importância da higiene e segurança alimentar no preparo de refeições, aplicando as Boas Práticas de Manipulação de Alimentos (BPMA) e dos Procedimentos Operacionais Padronizados (POPs) fundamentadas pela Resolução RDC n²16/04 ANVISA. Nos resultados e observações feitas validou-se que a falta de boas práticas por parte de alguns manipuladores compromete a segurança alimentar da população.
\end{abstract}

Palavras-Chave: Segurança dos alimentos, Saúde dos consumidores, Comércio ambulante.

\begin{abstract}
It is of great importance to apply Good Standard Handling Practices and Operating Procedures in all food services, considering that the hygiene and awareness of food handlers is one of the main sources of contamination. The present work presents the activities developed in partnership with the Municipal Health Surveillance of the municipality of Garanhuns / PE. Thus, the general objective of this work was to evaluate the hygienic conditions of these establishments, based on current sanitary legislation. Follow-up, guidance and training were carried out with street vendors and establishments during the official festivities of the city calendar in order to reduce the contamination risks as much as possible, using quality tools, to work on the need and importance of hygiene and safety food in the preparation of meals, applying Good Food Handling Practices (BPMA) and Standard Operating Procedures (POPs) based on Resolution RDC n 216 / 04 ANVISA. In the results and observations made, it was validated that the lack of good practices on the part of some handlers compromises the food security of the population.
\end{abstract}

Keywords: Food safety, Consumer health, Street commerce.

\footnotetext{
${ }^{1}$ Engenharia de Alimentos, Universidade Federal do Agreste de Pernambuco, eng.mirellycosta@gmail.com

${ }^{2}$ Doutora em Biotecnologia, Universidade Federal do Agreste de Pernambuco, gerla.chinelate@ ufape.edu.br
} 


\section{Introdução}

A comercialização de alimentos por ambulantes pode causar um grande risco para a saúde dos consumidores, se os alimentos não forem ofertados a população de maneira correta, seja pela falta de estrutura física adequada ou manipuladores de alimentos que não são capacitados, o que torna a segurança alimentar um grande desafio, já que esse tipo de comércio ambulante pode se instalar em vias públicas, parques, festividades e outros, fazendo assim que seja mais difícil o controle de qualidade e segurança dos alimentos. A falta de conhecimento, informação e investimento nesses pequenos estabelecimentos de alimentação reproduzem uma baixa qualidade dos alimentos e produtos comercializados.

Em estabelecimentos comerciais de alimentos, é de grande prioridade que qualidade seja garantida, posto que a cada dia que se passa só aumenta o hábito de realizar refeições fora de casa. Segundo dados do IBGE, o brasileiro gasta cerca de $25 \%$ de sua renda com alimentação fora do lar. A Associação de Bares e Restaurantes (ABRASEL) estima que o setor represente, hoje, 2,7\% do PIB brasileiro. Já a Associação Brasileira das Indústrias da Alimentação (ABIA) destaca que o setor tem crescido a uma média anual de 14,2\%. (SEBRAE,2019). Esses serviços apresentam grandes vantagens para o consumidor, como uma grande variedade de opções, uma rapidez de atendimento e custos acessíveis. No entanto, existem alguns elementos preocupam os órgãos responsáveis pela fiscalização da área de alimentação, tais como a insegurança dos alimentos, pelo maior tempo de exposição em temperaturas inadequadas. Além de mostrar a legislação, os programas de Boas Práticas devem sensibilizar o profissional para a adoção de boas práticas operacionais na manipulação, preparo e comércio de alimentos mais seguros (SOUZA et al., 2015). Além disso, alimentação fora do lar se tornou uma alternativa viável economicamente, por todas suas facilidades e por ser também uma forma de sustento para as famílias, a alimentação na "rua" pode ser considerada uma manifestação cultural local, que vai além da função nutricional, oferecendo muitas vezes uma experiência gastronômica aos consumidores (PERTILE, 2013).

Por esse motivo é fundamental a implantação de Boas Práticas de Manipulação (BPM) e de ser necessário uma rigorosa fiscalização, para que sejam evitadas as Doenças Transmitidas por Alimentos (DTA's) que são originadas do consumo de alimentos e bebidas contaminadas, que podem comprometer a saúde dos consumidores, levando assim um risco para a população.

O Manual de Boas Práticas (BPM) é um documento que descreve as operações realizadas pelo estabelecimento incluindo, no mínimo, os requisitos sanitários dos edifícios; a manutenção e a higienização das instalações, dos equipamentos e dos utensílios; o controle da higiene e saúde dos manipuladores; o controle e garantia de qualidade do produto final. Além 
disso, objetiva descrever os procedimentos adotados para atender os requisitos às Boas Práticas, incluindo desde aspectos de higiene pessoal, projetos e instalações, limpeza e sanitização de equipamentos e utensílios, até controles aplicados aos processos para assegurar a produção de alimentos seguros (ANVISA, 2006). Doenças transmitidas por alimentos (DTA) são aquelas causadas pela ingestão de alimentos e/ou água contaminados. Existem mais de 250 tipos de DTA no mundo, sendo que a maioria delas são infecções causadas por bactérias e suas toxinas, vírus e outros parasitas.

\section{Material e Métodos}

O trabalho foi desenvolvido no município de Garanhuns- PE, de início, foram realizadas reuniões na VISA, para discussão a respeito das atividades a serem realizadas em dois grandes eventos no município: Festival Viva Dominguinhos e Festival de Inverno de Garanhuns, com a definição dos procedimentos a serem seguidos. Todos os comerciantes cadastrados para trabalharem nos eventos passaram por análises documentais, tais como certificados de funcionamento e demais documentos para que fosse liberado o funcionamento e a comercialização, como o diagnóstico geral do setor de produção de alimentos dos estabelecimentos envolvidos no projeto segundo a RDC №216 de 15 de setembro de 2004, que dispõe sobre o Regulamento Técnico de Boas Práticas para os Serviços de Alimentação. Os requisitos avaliados serão relativos a Higienização das instalações, equipamentos, móveis e utensílios; Controle da potabilidade da água; Higiene e saúde dos manipuladores; Manejo dos resíduos; Manutenção preventiva e calibração de equipamentos; Controle integrado de vetores e pragas urbanas; Seleção das matérias-primas, ingredientes e embalagens e Programa de recolhimento de alimentos.

Durante os encontros foram realizados treinamentos através do curso de capacitação para os ambulantes devidamente cadastrados, em parceria com o SEBRAE de Garanhuns. Onde também foram realizadas reuniões e feitos acompanhamentos nos pontos de comércio ambulante de alimentos e bebibas, juntamente com os agentes e fiscais da Vigilância Sanitária (ANVISA) do município, para que fosse feito um diagnóstico das condições higiênicosanitárias dos mesmos, e análise de verificação de aplicação das Boas Práticas de Manipulação (BPM) e Boas Práticas de Fabricação (BPF) que são baseadas nas Resoluções RDC n . 216/2004, e na RDC n . 275/2002.

\section{Resultados e Discussão}

O treinamento dos manipuladores de alimentos envolve atividades com o objetivo de 
capacitar para o preparo de alimentos, por meio de mecanismos que possibilitem a transmissão dos conceitos importantes sobre as técnicas operacionais e de informações sobre o controle higiênico sanitário.

A capacitação dos ambulantes foi ministrada através de reuniões e palestras, onde foi trabalhado a respeito de como os manipuladores de alimentos deveriam se portar e sobre os procedimentos de higiene e limpeza dos equipamentos e alimentos, contaminação alimentar, uso correto dos uniformes, higienização das mãos, e todos os cuidados necessários para foi distribuído um material de auxilio, que continham todas a instruções e orientações a respeito de como garantir uma qualidade e segurança alimentar e também uma Cartilha de Boas Práticas de Manipulação elaborada pela aluna de extensão como parte do projeto.

Durante os dias e as noites dos festivais foram feitos acompanhamento em todas as barraquinhas dos ambulantes que estavam presentes, aos cadastrados foi feita a verificação se estavam dentro das normas estabelecidas pela RDC (Figura 1). Os comerciantes que não estavam dentro do padrão estabelecido sofreram apreensão de seus alimentos e novamente orientados a respeito das normas.

Durante o acompanhamento foram verificadas as condições higiênico-sanitárias dos pontos de comércio, formas de armazenamento, distribuição e exposição dos alimentos comercializados, e também analise de validade e condições físicas dos mesmo, foi observado também o comportamento dos ambulantes desde a abordagem inicial, durante a observação de alguns problemas encontrados: nas instalações; bancadas e utensílios; exposição, manipulação, armazenamento dos alimentos até a etapa final de orientação e conscientização quanto aos princípios de manipulação e segurança alimentar a ser tomados, da parte de alguns manipuladores ouve uma certa resistência a aplicação dos métodos de Boas Práticas, mais ao longo da orientação e explicação dos riscos, foi visto que a conscientização a respeito da segurança alimentar. A respeito das problemas encontrados em utensílios e até mesmo em produtos fora da data de validade e/os impróprios para consumo, os mesmos foram recolhidos e foi feito uma advertência e orientação ao ambulante responsável, foi encontrado em uma das barracas queijo, refrigerantes e ervilhas vencidos, colheres de pau, e com refeições sendo servidas sem a devida refrigeração, o que facilita a contaminação dos alimentos, levando riscos à saúde dos consumidores. 
Figura 1. Visitas aos ambulantes juntamente com a equipe da Vigilância Sanitária Municipal.

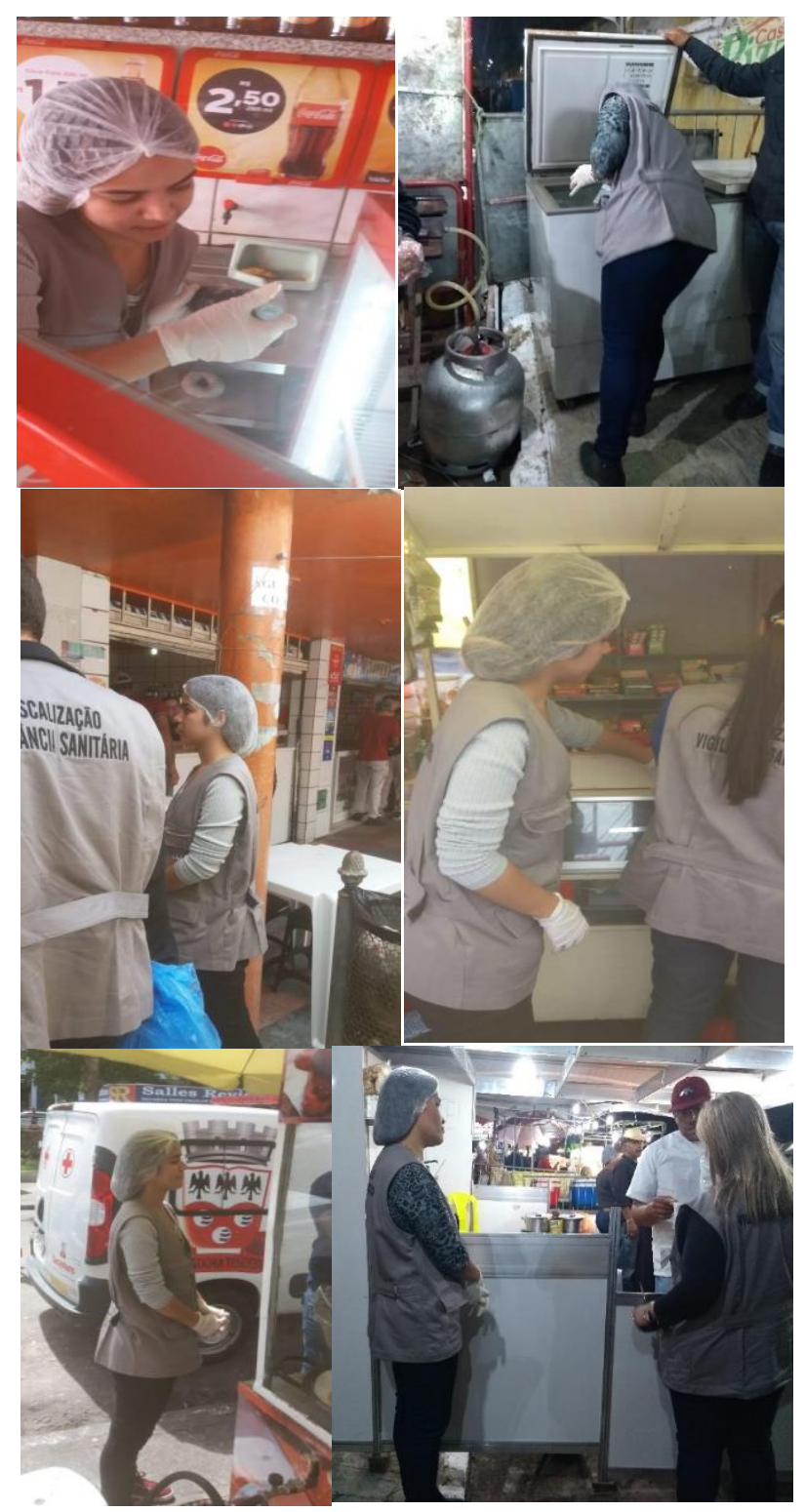

A cartilha distribuída foi elaborada a partir de ferramentas de qualidade, de acordo com a legislação vigente, utilizando as metodologias de Boas Práticas de Manipulação e dos Procedimentos Operacionais Padronizados (POPs), e também seguindo a Resolução RDC n²16/04 ANVISA. A cartilha completa pode ser verificada no Apêndice.

É necessário ressaltar que esses treinamentos devem ser atualizados, sempre que for necessário. Pode ser feito de duas formas: expositiva e prática, aumentando a motivação e a capacidade de resolução e prevenção dos problemas diários da empresa por meio de reflexões sobre situações já vivenciadas. A qualidade dos alimentos é um sistema preventivo, com disposição de controles e condições de trabalho que antecipem os problemas, seguido de 
programas, ferramentas, procedimentos e normas. As ações para garantir a qualidade exigem o comprometimento de toda a equipe envolvida direta e indiretamente no processo produtivo (SENAI, 2003). Mesmo com a capacitação e orientação prévia feita nas reuniões, a ausência de alguns ambulantes gera dificuldades no ato de manter a segurança da população, e isso merece preocupação, sendo necessária uma educação sanitária mais precisa e que seja feito um trabalho maior e constante com esses ambulantes, no mais amplo sentido, que deverá alcançar não somente a capacitação mais reduzir os hábitos e costumes tradicionais que, por si só, criam um risco à saúde. Por esse motivo devem haver programas de capacitação e reciclagem de aperfeiçoamento constante para os ambulantes, a fim de assegurar que as normas e os princípios higiênico-sanitários sejam respeitados. É de grande importância também que os órgãos responsáveis fiscalizem constantemente os ambulantes, somente assim será possível certificar o controle da saúde do consumidor.

\section{Conclusões}

A realização de ações educativas direcionadas aos ambulantes e além de campanhas educativas constantes onde deve ser trabalhado a respeito das Boas Práticas de Manipulação de Alimentos, os conscientizando a respeito dos riscos que eles podem estar levando a população e a eles mesmo se não seguirem com as normas estabelecidas. É necessário persistência e dedicação por parte dos órgãos públicos, nesses trabalhos e além de apoio e interesse dos ambulantes e uma maior exigência dos consumidores, já que durante o trabalho foi observado grande resistência da parte de alguns ambulantes.

\section{Referências}

BRASIL. Agência Nacional de Vigilância Sanitária. Cartilha sobre boas práticas para serviços de alimentação: RDC n⿳0 216/2004. Brasília, 2004.

BRASIL. Ministério da Saúde. Agência Nacional de Vigilância Sanitária. Resolução RDC n. 216, de 15 de setembro de 2004. Dispõe sobre regulamento técnico de boas práticas para serviços de alimentação. Diário Oficial [da] República Federativa do Brasil, Brasília, 16 set. 2004. p. 1-10.

BRASIL. Ministério da saúde. Doenças transmitidas por alimentos: causas, sintomas, tratamento e prevenção. Disponível em: < http://www.saude.gov.br/saude-de-a-z/doencastransmitidas-por-alimentos>. Acesso: em: 26 de out. 2019.

SACCOL, A.L.F. et al. Lista de avaliação de boas práticas para serviços de alimentação: RDC 216/2004, ANVISA. São Paulo: Varela, 2006. 47p.

SANTOS, Ruama Araújo. SEBRAE. Mercado de alimentação fora do lar, 2019. Disponível 
em: < https://m.sebrae.com.br/sites/PortalSebrae/ufs/ac/artigos/alimentacao-fora-dolar,19cfb3656dc20610VgnVCM1000004c00210aRCRD > . Acesso: em 26 de out. 2019.

SENAI. Trabalhando com segurança na produção de alimentos. Rio de Janeiro, SENAI/DN. 32p (Série Qualidade e Segurança Alimentar) Projeto APPCC. Convênio CNI/SENAI/SEBRAE. (2003).

SILVA JR. E. A. Manual de Controle Higiênico Sanitário em Alimentos. $4^{\mathrm{a}}$ Edição. São Paulo. Editora Varela, 2001.

SIQUEIRA, Treinamento sobre higiene e controle de qualidade para manipuladores de alimentos de uma unidade de alimentação e nutrição. Revista Higiene Alimentar, São Paulo, v. 22, n.166/167, dez.2005. p. $32-37$.

SOUZA, G. C. et al. Comida de rua: avaliação das condições higiênico-sanitárias de manipuladores de alimentos. Ciência \& Saúde Coletiva, v. 20, n. 8, p. 2329-2338, 2015.

VEIGA, C.F. et al. Estudo das condições sanitárias dos estabelecimentos comerciais de manipulação de alimentos no município de Maringá, PR. Hig. Aliment., São Paulo, v. 20, n. 138, p. 28-36, 2006.

Segundo pesquisa, $34 \%$ dos brasileiros gastam com alimentação fora do lar. Exame.abril.com.br. 28 abril de 2017. Disponível em: <https://exame.abril.com.br/negocios/dino/segundo-pesquisa-34-dos-brasileiros-gastam-comalimentacao-fora-do-lar-shtml/> Acesso em: 26 de out. 2019. 


\section{CARTILHA DE BOAS PRÁTICAS DE MANIPULAÇÃO DE ALIMENTOS}

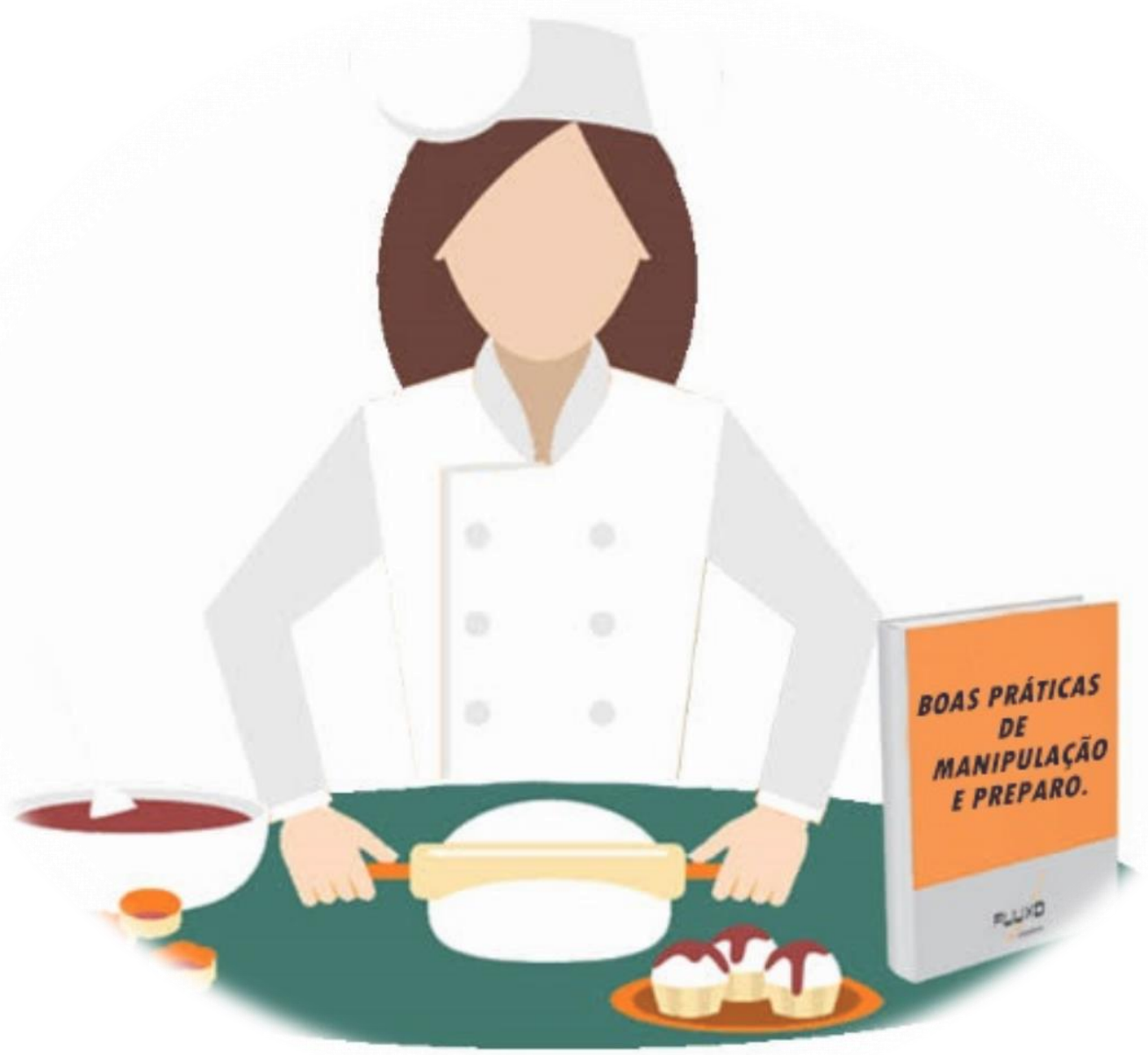




\section{SUMÁRIO}

APRESENTAÇÃO

O QUE SÃO BOAS PRÁTICAS DE MANIPULAÇÃO?

3

O QUE É O MANUAL DE BOAS PRÁTICAS DE MANIPULAÇÃO (BPM)? — 4

O QUE É PROCEDIMENTO OPERACIONAL PADRONIZADO (POP)?

QUEM É O MANIPUADOR?

- ONZE REGRAS ESSENCIAIS PARA O MANIPUADOR

DOENÇAS TRANSMITIDAS POR ALIMENTOS (DTA)

TIPOS DE CONTAMINAÇÃO E RISCOS

COMO CONTROLAS OS RISCOS? IMPLANTANDO AS BPM!!!

- LAVAGEM CORRETA DAS MÃOS:

- COMO DEVE SER O LOCAL DE TRABALHO:

- CUIDADOS QUE DEVEM SER TOMADOS COM OS INGREDIENTES NO PREPARO DE ALIMENTOS:

A COMIDA ESTÁ PRONTA, VAMOS SERVI-LA DE MANEIRA CORRETA?_ 11

E O LIXO? O QUE FAZER 


\section{APRESENTAÇÃO}

É necessário estabelecer procedimentos de Boas Práticas para serviços de alimentação a fim de assegurar condições higiênico-sanitárias do alimento preparado e saúde aos consumidores, deve existir a aplicação das Boas Práticas de Manipulação nos serviços de alimentação que exercem as seguintes atividades: como a manipulação, no preparo, armazenamento, distribuição, exposição à venda e entrega de alimentos preparados ao consumo, tais como cantinas, bufês, confeitarias, cozinhas industriais, cozinhas institucionais, lanchonetes, padarias, pastelarias, e restaurantes seguindo as normas estabelecidas pela RDC $N^{\circ} 216$ ANVISA - Agência Nacional de Vigilância Sanitária. 


\section{O QUE SÃO BOAS PRÁTICAS DE MANIPULAÇÃO?}

São práticas de higiene que devem ser obedecidas pelos manipuladores de alimentos, desde a escolha e compra dos produtos a serem utilizados no preparo do alimentos até a vendo para o consumidor. $O$ objetivo das Boas práticas de manipulação é evitar a ocorrência de doenças provocadas pelo consumo de alimentos contaminados, $o$ que leva risco à saúde do consumidor e do manipulador.

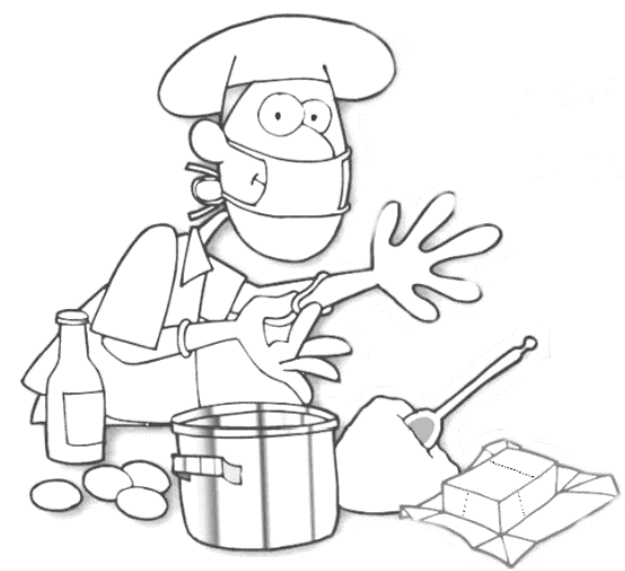

IMAGEM: GOOGLE

\section{O QUE É O MANUAL DE BOAS PRÁTICAS DE MANIPULAÇÃO (BPM) ?}

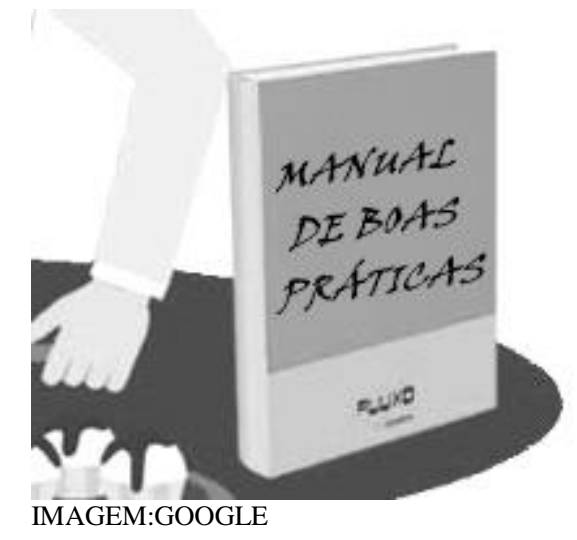

O manual de Boas Práticas é um documento que descreve $o$ trabalho executado no estabelecimento e a forma correta de fazê-lo. Nele, pode-se ter informações gerais sobre como é feita a limpeza, o controle de pragas, da água utilizada, os procedimentos de higiene e controle de saúde dos funcionários, o treinamento de funcionários, o que fazer com o lixo e como garantir a produção de alimentos seguros e saudáveis.

\section{O QUE É PROCEDIMENTO OPERACIONAL PADRONIZADO (POP)?}

O Procedimento Operacional Padronizado (POP) é um documento que descreve passo-a-passo como executar as tarefas no estabelecimento. É como uma receita de bolo, que deve ser seguida rigorosamente, para que tudo vá bem. O POP destaca as etapas da tarefa, os responsáveis por fazê-la, os materiais necessários e a frequência em que deve ser feita. Como os POP são documentos aprovados pelo estabelecimento, por meio do responsável, é dever de cada manipulador segui-los. 


\section{QUEM É O MANIPUADOR?}

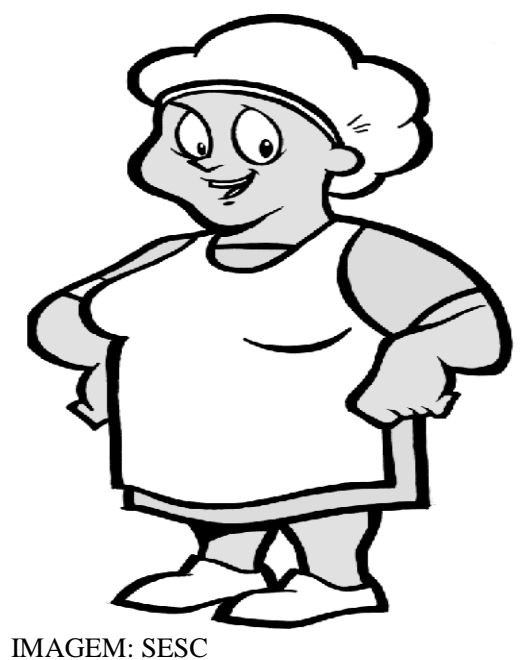

Todas as pessoas que trabalham com alimentação são consideradas "manipuladores de alimentos", ou seja, quem produz, coleta, transporta, recebe, prepara e distribui o alimento, é dever do mesmo fazer a segurança do alimento para evitar as Doenças Transmitidas por Alimento (DTA)

\section{ONZE REGRAS ESSENCIAIS PARA O MANIPUADOR}

\section{ENQUANTO ESTIVER MANIPULANDO ALIMENTOSNÃO SE DEVE:}

\footnotetext{
1- COÇAR

2- FALAR, TOSSIR OU ESPIRRAR SOBRE OS ALIMENTOS

3- COLOCAR O DEDO NO NARIZ, NA ORELHA OU NA BOCA

4- ASSOAR O NARIZ

5- CUSPIR NO CHÃO DO LOCAL DE TRABALHO.

6- MASCAR CHICLETES, PALITOS OU OUTRAS COISAS PARECIDAS

7- PENTEAR NEM PASSAR AS MÃOS NO CABELO

8- FUMAR NOS AMBIENTES DE PREPARO, MANIPULAÇÃO E ARMAZENAMENTO DE ALIMENTOS.

9- PROVAR ALIMENTOS COM AS MÃOS OU PROVAR COM TALHERES E COLOCÁ-LOS DE NOVO NA PANELA SEM ANTES HIGIENIZÁ-LOS

10- MEXER EM DINHEIRO

11- USAR UTENSÍLIOS NÃO HIGIENIZADOS PARA MEXER OU SERVIR ALIMENTOS
}

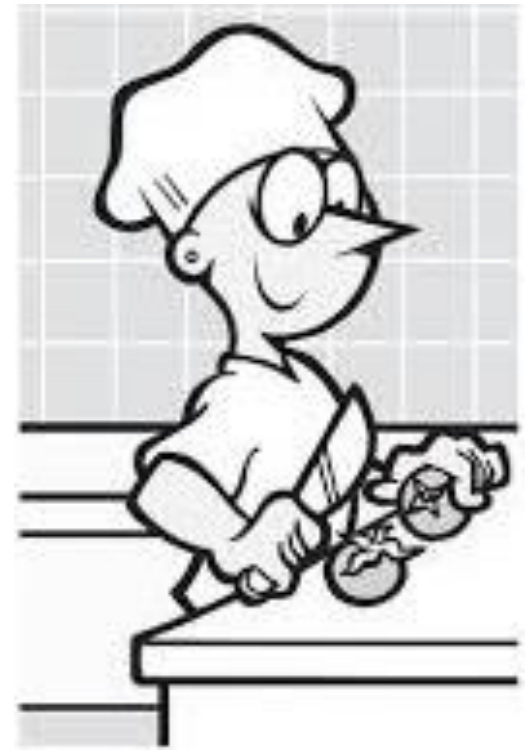

\section{DOENÇAS TRANSMITIDAS POR ALIMENTOS (DTA)}

São doenças provocadas pelo consumo de alimentos que ocorrem quando microrganismos prejudiciais à saúde, parasitas ou substâncias tóxicas estão presentes no alimento. Os sintomas mais comuns de DTA são vômitos e diarreias, podendo também apresentar dores abdominais, dor de cabeça, febre, alteração da visão, olhos inchados, dentre outros. Para adultos saudáveis, a maioria das DTA dura poucos dias e não deixa sequelas; já para as crianças, as grávidas, os idosos e as pessoas doentes, as consequências podem ser mais graves, podendo inclusive levar à morte. 


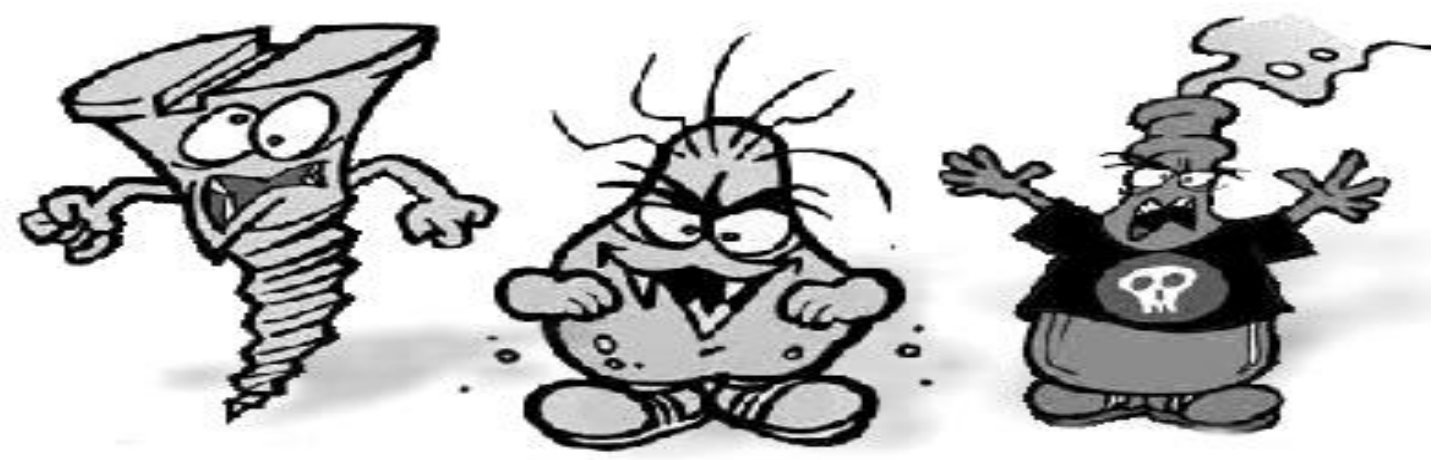

IMAGEM: GOOGLE

\section{TIPOS DE CONTAMINAÇÃO E RISCOS}

A contaminação pode ocorrer de três maneiras, através da contaminação por parasitas, microrganismos e contaminação física.

- Contaminação por parasitas:

Os parasitas como: ameba, giárdia e vermes podem estar presentes no solo, na água e no intestino dos homens e dos animais, podendo então contaminar os alimentos e causar doenças. Na contaminação por parasitas, deixar lixo exposto, ambiente sujos e desorganizados são os lugares mais oportunos para vetores de contaminação, como: ratos, baratas e outros insetos.

- Contaminação por Microrganismos:

Se não forem tomados alguns cuidados, os micróbios que contaminam o alimento podem se multiplicar rapidamente e causar doenças; Na contaminação por Microrganismos, não podem ser vistos a olho nu, e são umas dos maiores contaminadores de alimentos, apresentam diversas formas como: bactérias, fungos $e$ vírus, nem sempre alteram o odor e sabor dos alimentos agindo silenciosamente. Deve se manter as mãos sempre limpas, ao chegar no trabalho, quando espirrar, tossir ou assoar o nariz, depois de recolher o lixo, pegar em dinheiro, ou usar o banheiro. Os micróbios multiplicam-se nos alimentos quando encontram condições ideais de nutrientes, umidade e temperatura.

- Contaminação Física:

Qualquer corpo estranho encontrado no alimento, como pequenos pedaços de vidro ou madeira, insetos, metais ou cabelo; Na contaminação física, pode estar no estouro de uma lâmpada, na utilização de colher de pau, por essa maneira se deve fazer a manutenção dos equipamentos, para evitar que alguma parte solte, manter tudo sempre organizado $e$ limpo; fazer sempre a barba e o bigode e manter as unhas curtas sem esmalte e base. 


\section{OS RISCOS ESTÃO EM TODA PARTE!!!}
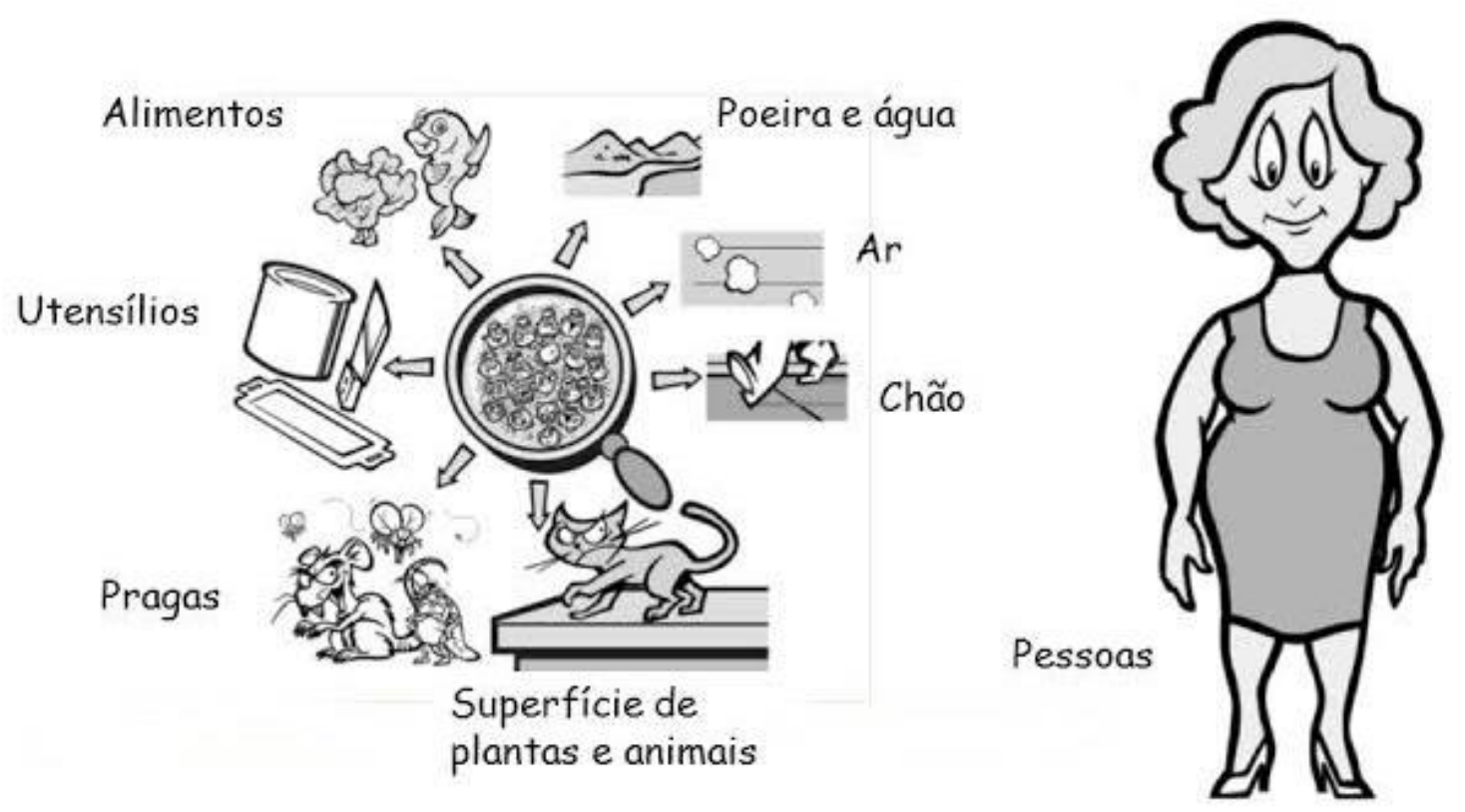

IMAGEM:SESC

\section{COMO CONTROLAS OS RISCOS? IMPLANTANDO AS BPM!!!}

As Boas Práticas são regras que, quando praticadas, ajudam a evitar ou reduzir os perigos.

As Boas Práticas envolvem:

- adequação e manutenção das instalações;

- prevenção da contaminação por utensílios, equipamentos e ambientes;

- prevenção da contaminação por colaboradores;

- prevenção da contaminação pelo ar ambiente (ar condicionado, condensação etc.);

- prevenção da contaminação por produtos químicos;

- controle de pragas;

- garantia da qualidade da água (ex: limpeza da caixa d'água);

- cuidado com o lixo. 


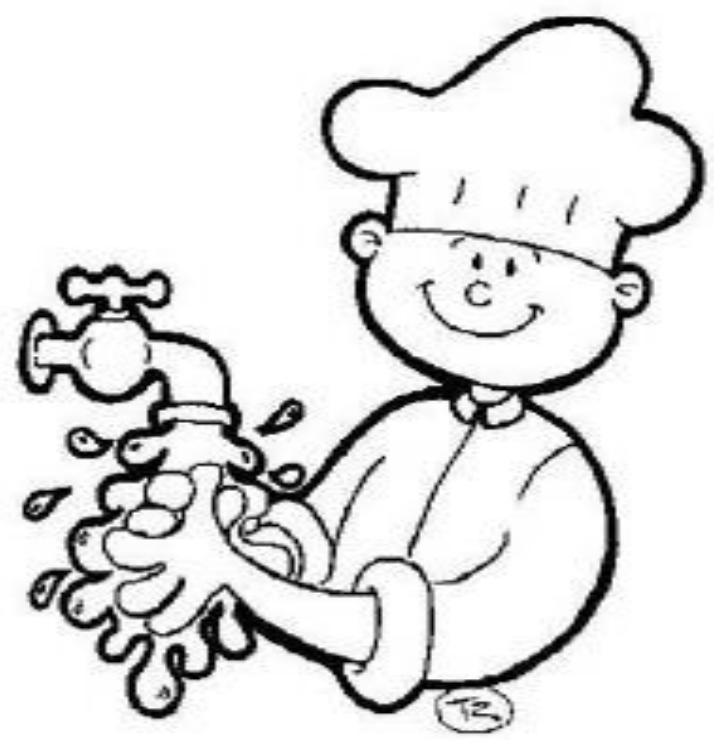

IMAGEM: GOOGLE

- LAVAGEM CORRETA DAS MÃOS:

Para lavagem correta das mãos siga os seguintes passos:

1. Utilize a água corrente para molhar as mãos;

2. Esfregue a palma e o dorso das mãos com sabonete, inclusive

3.as unhas e os espaços entre os dedos, por aproximadamente 15 segundos;

3. Enxágue bem com água corrente retirando todo o sabonete;

4. Seque-as com papel toalha ou outro sistema de secagem eficiente;

5. Esfregue as mãos com um pouco de produto anti-séptico;
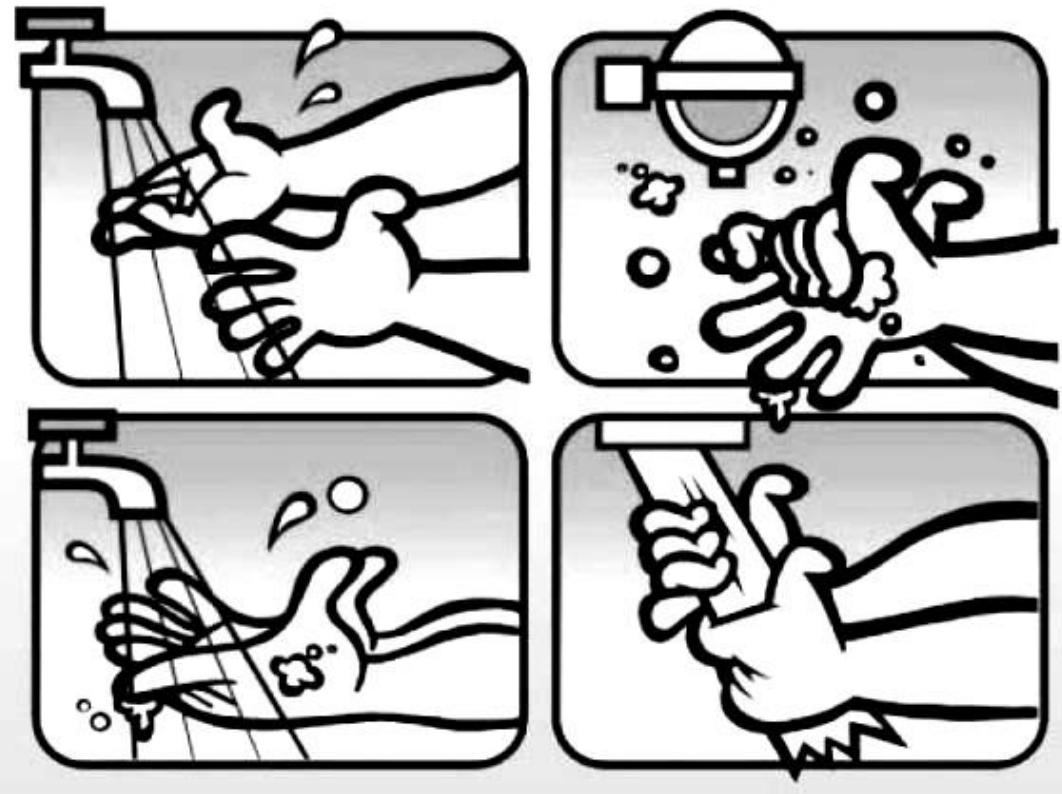

IMAGEM: GOOGLE 
- COMO DEVE SER O LOCAL DE TRABALHO:

$O$ ambiente de trabalho deve ser mantido sempre limpo e organizado, livre de bagunça, o chão da cozinha sempre limpo e varrido antes da produção, e nunca durante a produção dos alimentos, para evitar a poeira que pode se acumular sobre os alimentos, móveis e utensílios devem ser guardados em lugares limpos e secos, protegidos da poeira, moscas e outros insetos; equipamentos devem estar com manutenção em dia, em bom estado de conservação e limpos, durante a limpeza os mesmo devem ser desmontados e higienizados parte por parte.

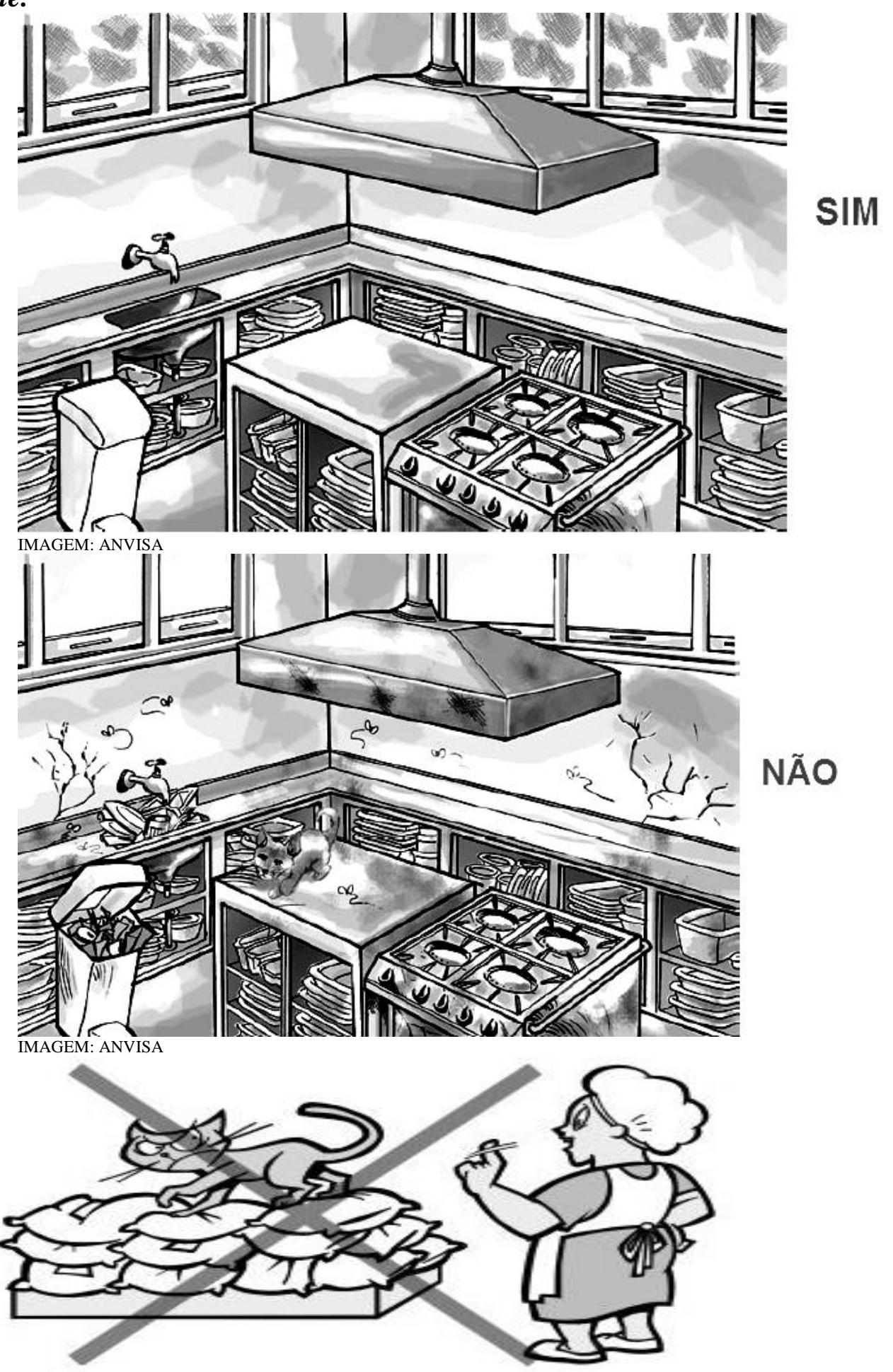

IMAGEM: SESC 
- CUIDADOS QUE DEVEM SER TOMADOS COM OS INGREDIENTES NO PREPARO DE ALIMENTOS:

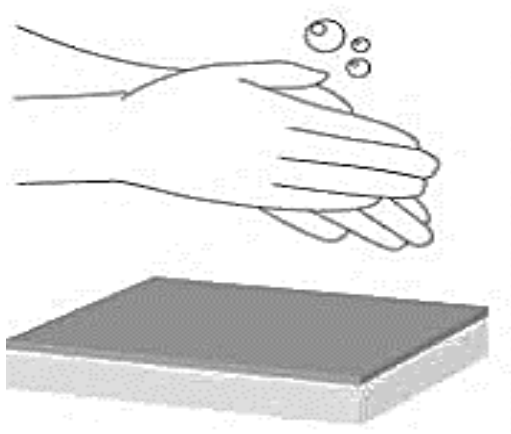

IMAGEM:GOOGLE.
PARA COMEÇAR...

Lave bem as mãos antes de usar a cozinha;

NA PIA...

Esponjas podem ter restos de comida, que favorecem o surgimento de bactérias

Não use a mesma água com sabão para lavar a louça várias vezes.

Não se deve utilizar utensílios de madeira na cozinha, pois a madeira é bastante absorvente e de dificil higienização, levando ao acúmulo de bactérias que pode vir a contaminar os alimentos que estão sendo preparados, os utensílios a serem utilizados devem ser feitos de alumínio ou vidro.

Não reutilize o mesmo utensílio para manipular alimentos diferentes, não deixe que alimentos crus se misturem aos prontos para consumo, não manipule alimentos já higienizados.

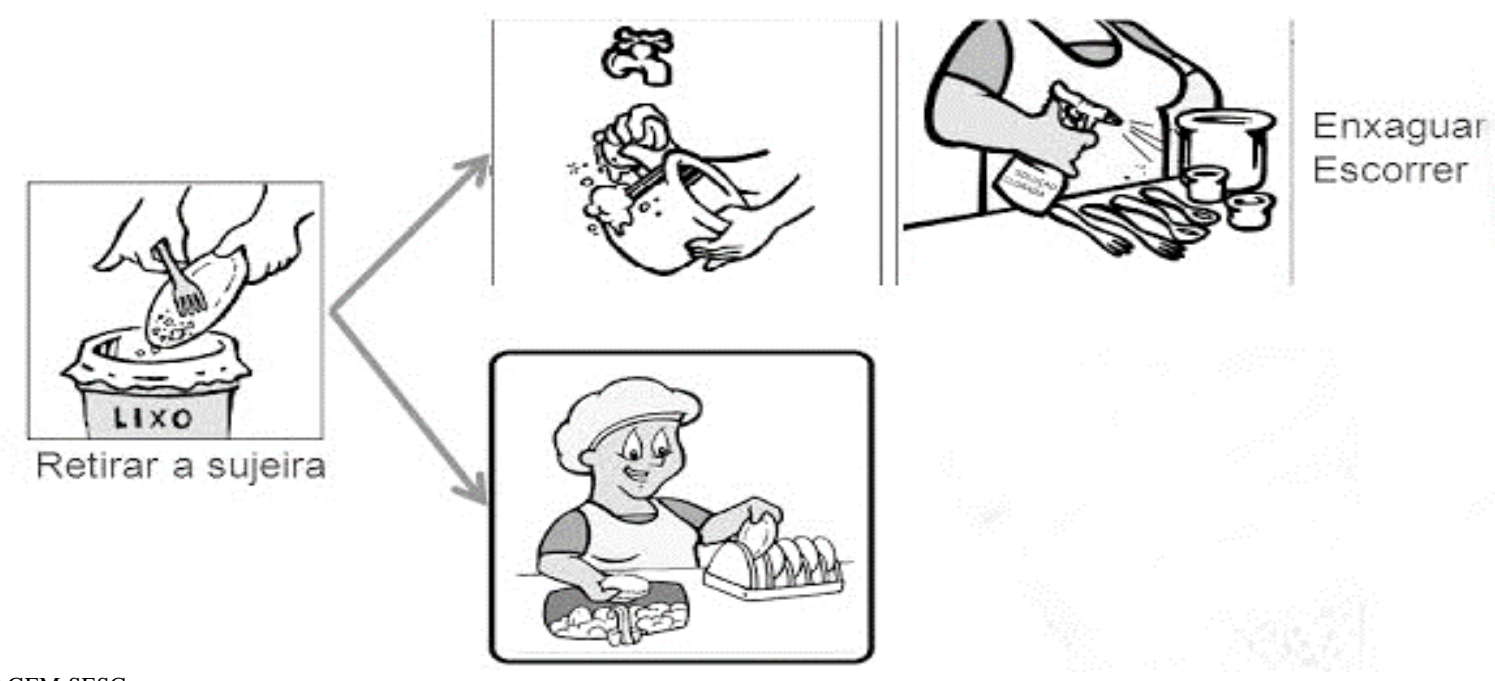

IMAGEM:SESC 


\section{Produtos que exigem mais cuidado}

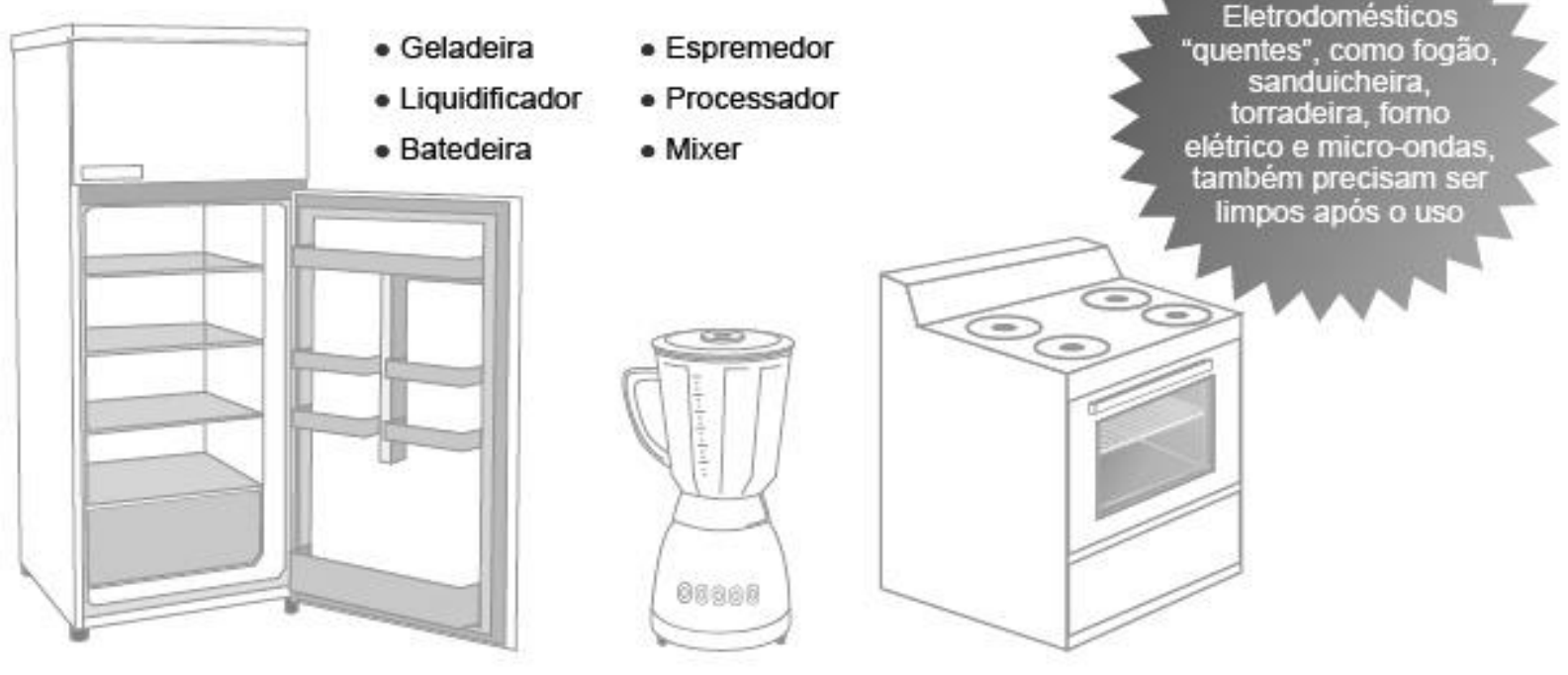

IMAGEM: GOOGLE

Não use ou compre produtos com embalagens amassadas, estufadas, enferrujadas, abertas ou com algum tipo de defeito. Deve-se limpar as embalagens antes de abri-las, os ingredientes que não forem totalmente usados devem ser armazenados em recipientes limpos e identificados com nome, data da abertura da embalagem e o prazo de validade.

\section{A COMIDA ESTÁ PRONTA, VAMOS SERVI-LA DE MANEIRA CORRETA?}

Os equipamentos (estufas, balcões, buffets, geladeiras, freezers, etc.) devem estar conservados, limpos e funcionando bem. A temperatura das estufas, bufês e geladeiras devem estar reguladas de forma que os alimentos quentes permaneçam acima de $60^{\circ} \mathrm{C} e$ os alimentos frios permaneçam abaixo de $5^{\circ} \mathrm{C}$. Procure diminuir ao máximo o tempo entre o preparo e a distribuição dos alimentos. Os balcões e bufês devem ser protegidos para que os clientes não contaminem os alimentos enquanto se servem. Os funcionários responsáveis por servir o alimento devem estar sempre com as mãos lavadas. Os funcionários que manipulam o alimento (mesmo com guardanapos, pegadores e talheres) não podem pegar em dinheiro. Os funcionários responsáveis por servir o alimento devem estar sempre com as mãos lavadas. Os funcionários que manipulam o alimento (mesmo com guardanapos, pegadores e talheres) não podem pegar em dinheiro. 


\section{E O LIXO? O QUE FAZER.}
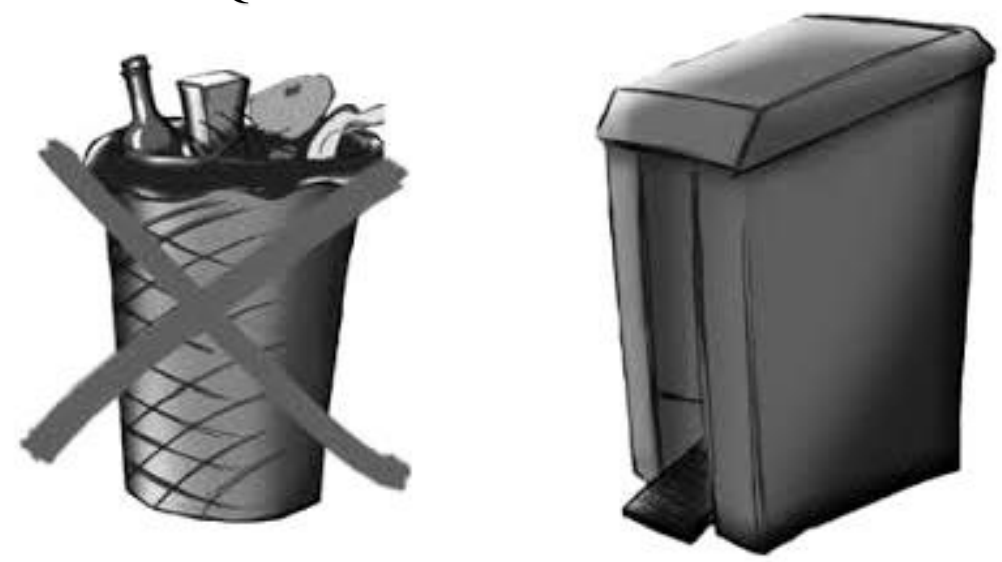

IMAGEM: SESC

A cozinha deve ter lixeiras de fácil limpeza, com tampa e pedal. Retire sempre o lixo para fora da área de preparo de alimentos em sacos bem fechados. Após o manuseio do lixo, deve se lavar as mãos.

O lixo pode atrais insetos e outros animais para a área de preparo dos alimentos, o que é um meio ideal para a multiplicação de microrganismos patogênicos.

\section{REFERÊNCIAS}

BRASIL. Agência Nacional de Vigilância Sanitária. Cartilha sobre boas práticas para serviços de alimentação: RDC nº 216/2004. Brasília, 2004.

SIQUEIRA, Treinamento sobre higiene e controle de qualidade para manipuladores de alimentos de uma unidade de alimentação e nutrição. Revista Higiene Alimentar, São Paulo, v. 22 , n.166/167, dez.2005. p. $32-37$. 